Article

\title{
Strategic Management of Crossmedia Production at Estonian Public Broadcasting
}




\section{ABSTRACT}

This article investigates the strategies behind the production of crossmedia content at Eesti Rahvusringhääling (ERR), Estonia's public broadcaster. The empirical work that supports its analytic objectives consists of multiple methodologically varying sub-studies: a textual analysis of ERR's existing online presence and crossmedia content; 32 semi-structured interviews with its various top- and mid-level managers; and a documentary analysis of its associated strategies, guidelines, and communications. The paper suggests that, despite ERR's advanced presence on digital platforms, it notably lacks a more comprehensive strategy for crossmedia content production and for achieving better inter-organisational cooperation that would enable new production processes. Although a few more advanced crossmedia productions have taken place, these have tended to emerge ad hoc - out of initiatives from individual employees. The article, however, suggests that, despite the current lack of an organisational strategy, the experiences acquired by its employees are creating a timely momentum for using interpretative and adaptive approaches to developing its new crossmedia production strategies.

\section{INTRODUCTION}

This article is about how the Estonian Public Service Broadcaster (Eesti Rahvusringhääling, ERR) is transforming itself in the era of media convergence. However, as has been successfully demonstrated by Anders Fagerjord and Tanja Storsul (2007), convergence is a concept with many implications. They have been distinguishing between "network convergence", "terminal convergence", "service convergence," "rhetorical convergence", "market convergence", and "regulatory convergence". Also "industry convergence" is often referred to in the dedicated academic discourse. All these dimensions of the convergence processes could be understood as being autonomous, but only to a certain extent. They are also interdependent, mutually conditioning, and co-evolving, however, in complex and nonlinear ways. Therefore, Fagerjord and Storsul (2007) suggested that the term should be understood as a useful rhetorical device that denotes the complexities of modern media evolution. For a media institution to manage its continuance in such an environment it must manage complexity, both outside as well as inside the organisation. Institutions normally respond to complexities by developing various kinds of strategies, either top-down or bottom-up, in more or less formal ways. One strategic response rather commonplace in Europe and elsewhere in recent years is multiplatform publishing, or, as it is also known, crossmedia production. In this article we will take a 
closer look at how ERR is implementing its crossmedia strategies and what the related objectives, rationales, challenges, and realities are.

\section{PUBLIC SERVICE MEDIA AND CROSSMEDIA PRACTICES}

Firstly, what do we mean by "crossmedia"? Crossmedia (also written as cross-media or cross media) is a term that surfaced in the first decade of the 21 st century to denote the evolving strategies and practices used by global media industries to develop content across multiple channels, especially including the new digital media platforms that enable new forms of interaction and audience participation. The technical convergence of communications networks and protocols has made it increasingly easy to repurpose or modify intellectual property for multiple media and, in this way, create new meaningful connections between distinct media platforms or associated "experiences". It is the experiments with such connectionmaking, motivated by both poetic potential (new storytelling techniques or other content presentation possibilities) as well as economic benefits that have been termed crossmedia strategies in contemporary culture.

When it comes to economic rationales, crossmedia strategies can be understood as one of the practical applications of what in media economics are known as "“diversification" strategies" (Chan-Olmsted, Chang 2003, 2006; Kolo, Vogt 2003; Küng 2008; Ibrus, Scolari 2012) that in turn are based on the "economies of scope and scale" logic of media economics. By building on the economies of scope logic, diversifying the forms and expressions of the existing intellectual properties, and spreading these across horizontal media markets, firms can generate additional revenue streams and cross finance product lines, thus providing themselves with an important instrument to manage market risk - i.e., spreading the risk across the media (Aarseth 2006; Küng 2008: 133; Ludwig 2000). As demonstrated by Sylvia M. Chan-Olmsted (2005), "consumer media scope", or the ability to knowledgeably cater to media consumers' behav- iour and preferences across platforms and formats, provides a potential competitive advantage. Related to this is the elicitation of "product spillovers", which occur when goods and services "increase demand for complementary goods in other sectors, which is an established merchandising and branding strategy in the cultural economy" (Chapain et al. 2010: 25).

In the internet economy a similar diversification strategy first became known as the COPE strategy: Create Once, Publish/ Play Everywhere (for instance, Huntsberger 2008). The idea behind COPE was that, by circulating the same items of content, users could choose how, when and where they consumed the content. The approach has also been criticised for being a cause of staff downsizing by "doing more with less people" (Deuze 2004: 143) and for "cloning" (Dailey et al. 2005), or so-called "shovelware" (Boczkowski 2004: 55), rather than producing new outputs offering unique medium-specific experiences or insights. However, such criticism on its own illustrates what these strategies have meant in economic terms - to build on the synergies of the economics of scope and cut the marginal cost relative to output. As Gillian Doyle (2010: 445) demonstrates, private media firms, especially commercial broadcasters, will continue to look for ways to improve returns from online distribution, complex windowing techniques - that is, the careful planning and sequencing of the release of content across multiple outlets to maximise audience value and/ or commercial returns. But she also suggests (ibid.) that the transition from a single-media to a multi-platform organisation involves notable additional costs. Audiences have come to expect ever more dedicated and sophisticated transmedia tie-ins, but meeting these demands can be costly (Soun Chung 2007: 55). The production of interactive content is labour- intensive and presumes significant investments in specialist skills. As a result, firms end up hiring ever growing numbers of dedicated staff for producing and reproducing content for increasing numbers of platforms, while only some of these will be successful in generating 
incremental revenues to a level that enables marginal costs to be covered (Erdal 2009). Still, when it comes to motives that condition change, then, as suggested by Doyle (2010: 440), moving to multi-platform distribution is usually traceable to expectations of long-term profit maximisation.

However, it should be noted that for public service media (PSM) institutions the primary concern is public value and audience welfare rather than profits and so strategic motives are more wide-ranging. Historically, it is universal coverage, the provision of a free service accessible to all that has been considered to be one of the most important PSM principles because of the social value of mass audience reach - understood to condition the emergence of a shared public space for public discourse. In the digital era a new consensus has emerged that on-demand, crossplatform access is the new universality. As explained by Mary Debrett (2009: 810), in the digital era, when media services and the media habits of the fragmented audience are increasingly diverse, access is no longer about scarcity, therefore universality needs to be addressed across the full range of media platforms in order to aggregate sufficient fragments to reach a general public. In a crossmedia context, "serving" no longer means "always", "at the same time", or "in the same way", but using the affordances of each platform to address a certain type of audience and to fulfil specific goals (Suárez Candel 2012: 57). As also emphasised by Johannes Bardoel and Leen d'Haenens (2008: 353), new media technologies supplement rather than replace the old ones, and therefore, public content production will remain important in a context of abundant technology but relative scarcity of professionally produced content. Georgina Born (2004: 79) stresses that quality is a key challenge for public service systems in a pluralist society where access itself is no longer scarce. "Quality", in turn, is most often interpreted in terms of noncommercial production values that also include creative risk-taking and is applied both in factual and narrative programming across popular, as well as high, culture genres. The implementation of "quality" as diversity and innovation is given an advantage by the intrinsic traits of digital media - personalisable, interactive, searchable, shareable, mobile, and available on-demand (Debrett 2009: 812). Debrett also stresses that multiplatform projects tend to extend the shelflife and reach of publicly funded productions, building on virally evolving publicities on social networking sites, and thereby help to maximise the value of public investment. Furthermore, due to convergence and digitisation, television itself is changing in ways that make it increasingly difficult to consider linear broadcasting in isolation from other modes of distribution to audiences, such as the internet and mobile (Trappel 2008; Creeber, Hills 2007; Caldwell 2006).

Consequently, many public service broadcasters are motivated to follow their audiences wherever they are, or whatever platforms or media technologies they may be using. This is even truer as the interactive and participatory affordances of digital media enable the PSBs to establish ever more engaged and intensive relationships with audiences. For this reason, online audiences are increasingly viewed not as a marginal or secondary, but rather a crucial, asset (Suárez Candel 2012: 43). That is, crossmedia strategies enable the fostering of audience interaction, participation and social integration and, by pursuing these goals, PSBs can renew their legitimacy by engaging and connecting communities in new ways (Debrett 2009: 813). Network technologies enable more direct dialogues with audiences, and this has created an opportunity to recreate the "ultimate" public service as an institutional platform for societal dialogues. As Petros losifidis (2010: 1) also observes: "[C]ross-platform strategies help public service media retain audience share, reach new audiences and develop on-demand services, while enabling them to create a stronger partnership with civil society and serve an extended form of citizenship."

In the European broadcasting domain, all these rationales and realisations have 
created a situation where public broadcasters tend to be the driving forces and innovators in the area of convergent media and online distribution (Moe 2008; Ibrus, Ojamaa 2014). Compared to private broadcasters, they are generally more inclined to finance more experimental multiplatform projects due to their structural objectives and therefore function as innovation engines for the whole media services ecosystem - a function often ascribed to PSBs across Europe (Bechmann 2012: 903). For instance, as reported by James Bennett et al. (2012: 6), in the UK there is evidence that such a function has been carried out with positive results. The two large British PSBs - the BBC and Channel 4 - being committed to multiplatform commissioning have effectively "incubated" a number of new companies dedicated to digital content and have more broadly generated economic value and growth in the independent sector, eventually helping to make the UK a world leader in multiplatform content production. Therefore, Bennett et al. (ibid.) propose that there is a "compact" between the PSBs and the independent sector that has contributed to making UK content unique and exportable.

\section{CHALLENGES TO CROSSMEDIA MANAGEMENT AT LARGE MEDIA ORGANISATIONS}

In most countries, public service media institutions are relatively large organisations, often well positioned and popular among audiences. They have their brands and relationships with citizens well established and deeply embedded in the everyday cultures of these societies. Yet, these same legacy relationships may turn into challenges when such large organisations need to be innovated and new strategies or objectives need to be developed and implemented. Many management studies have revealed the difficulties that are encountered within organisations related to the mobilisation of people with regard to innovations (Bulck, Tambuyzer 2013: 57). If management does not have a good understanding of how to lead the convergence process, the practical development of crossmedia productions can result in uncertainty and journalistic resistance as new working processes and norms are introduced (García-Avilés 2012: 271). The current organisational structure of ERR is such that the teams for different platforms work separately in different buildings and most of the editors and reporters produce content for only one medium. Therefore, the strategic challenge is how to achieve cooperation and collaboration between formerly distinct media newsrooms and other editorial offices of the media institution (see Deuze 2004: 140). In such situations, managers play an important role in helping journalists to recognise the best ways for developing better cooperation across platforms. As it has been recognised, this may often be challenging and presumes a wide knowledge base:
Managers need a broader, deeper and more up-to-date knowledge about technical innovation, mar- ket trends, content production possibilities and viewing/con- sumption patterns. Overall, as workflows become more complex, a multimedia and multiplatform vision is required not only to take the right decisions but also to be able to motivate and empower the staff so the goals pursued are achieved. (Suárez Candel 2012: 71)

Motivating the staff is perhaps one of the core challenges as the evidence from several countries indicates. For instance, Tamara Witschge and Gunnar Nygren (2009) have demonstrated how Swedish and British journalists tend to be sensitive about convergence resulting in journalism mainly becoming a desk job. Also Mark Deuze (2004) has demonstrated how journalists and media producers tend to criticise the COPE strategy (described above) for being a matter of staff downsizing by "doing more with less people" and for compromising journalistic integrity by failing to take specific media characteristics into consid- 
eration (Singer 2004; see also Huang et al. 2004).

Another common managerial challenge that has become evident in complex and converging media organisations is the "cultural clashes" between the professionals that used to work for different media, but are now finding themselves cooperating in various ways. Members of an organisation can belong to several different subsystems: professional cultures (groups of practitioners who share a common base of knowledge, a common jargon and similar background and training), industry cultures (value orientations common to those working in a certain industry), and interorganisational subcultures (based around cultural groupings such as hierarchical levels, function departments, gender, and subgroups). According to Ivar John Erdal (2007), inter-organisational subcultures in media organisations can be based on different production environments (radio, TV, online) or hierarchical levels (management, news workers). While studying the convergence of radio and television newsrooms $\mathrm{B}$. William Silcock and Susan Keith (2006: 612) detected that there is a danger of cultural clashes if different inter-organisational cultures are forced to unite because journalists' identities are strongly connected to their primary medium.

Another challenge to convergence and crossmedia cooperation within organisations is the hierarchies of journalistic professions and different statuses that the different media may have. In the course of convergence processes and the emergence of online journalism, a new polarisation has often formed in which multimedia journalism is generally seen as less prestigious than working for one and more of the established media (Deuze 2004: 145). Yet, studying a regional office of the BBC, Simon Cottle and Mark Ashton (1999: 33), found that convergence may also lead to flattened hierarchies.

\section{STRATEGIC MANAGEMENT OF CROSSMEDIA INNOVATIONS}

As suggested above, many of the above described inter-organisational challenges may indeed emerge as thresholds for convergence and for implementing crossmedia strategies. Therefore, they require a strategic response from the organisation's management. But what kind? Academic research into strategic management as well as into media management has a history of more than half a century and, during this time, several schools and approaches have been developed. Below, we will review some of these and consider their relevance for analysing the ongoing challenges with regard to crossmedia strategies and convergence related transformations.

One group among the most established approaches to innovation strategies is known as the rationalist strategies. The focus of such strategies is on analysing external factors; for instance, how the general media system is evolving, and thereafter, developing strategic responses to these changes in the environment and eventually implementing this strategy systematically (Tidd, Bessant 2009: 165-170). Due to the analytic focus on external factors, the approach is also sometimes called externalist. In conceptual terms such approaches often build on Michael E. Porter's Five-Forces Model (Porter 1998), which in turn focuses on factors such as the bargaining power of buyers, the threat of new entrants, the bargaining power of suppliers, the threat of substitute products, and the existing rivalry between firms, in order to make assessments on the general situation that a company is in and to develop an appropriate strategy. The weaknesses of this approach include the following: firstly, especially at the time of convergence, the environment is changing too dynamically and appears too complex for developing strategies that could be used by the company to achieve their long-term goals; secondly, such strategies often tend to be developed by small managerial teams, and may not be fully accepted by the entire organisation, therefore making them difficult to implement (especially at times that require flexible operations). 
The second group of approaches are called either incrementalist (Tidd, Bessant 2009: 170) or adaptive (Küng 2008: 119). The underlying idea is still the same - change is endemic, it is both externally as well as internally conditioned and an organisation's future is dependent on its ability to transform itself from inside out on a daily basis - that is, to adapt incrementally. Such approaches are effectively based on the evolutionary economics view that equilibrium is rare and all changes are effected by entrepreneurs/institutions endogenously (and eventually all broader changes are effected by interactions between innovating institutions; see Mansell 2014). The focus of this approach to strategy development is on the interactions between the internal dynamics within organisations and their general environment. This means that strategy developments are understood as evolutionary processes - they emerge via everyday "actions upon actions" (to make a link to Michel Foucault's (2002) concept of governmentality), in the implementation process and are not planned very much in advance.

The third group, as it is explained by Lucy Küng, are the interpretative approaches to strategic innovation management. As she puts it, the interpretative approach seeks to understand organisations from the perspective of those working in them with a focus on how meaning is constructed out of events and phenomena and how the constructed meanings influence the behaviour of firms (Küng 2008: 122). The adaptive and interpretive approaches are similar because they emphasise the dynamics within organisations. Yet, while adaptive approaches focus more on changes that need to be carried out in regard to structures, work routines or technologies, the interpretative approaches focus on cultural changes and how these can be conditioned by modifying various kinds of cultural and social systems (including systems and patterns of communication) within the organisation. That is, a firm's behaviour is seen as an outcome of the complex processing of meanings by various professionals within the organisa- tion, of the dialogic practices among them, and, eventually, of the resulting collectively (dialogically) constructed new meanings on the goals, identities, and other values of the particular organisation and how these could be applied within the existing environment. It should be emphasised that such processing should be understood as continuous and complex, since there are multiple actors or social systems within the organisations whose perceptions and discourses may vary and whose dialogic practices both within the organisation as well as across its boundaries also take place in great numbers. Therefore, one of us has suggested previously (Ibrus 2013, 2014a, 2014b) that the emergence of institutional strategies is dependent on all such dialogic processes being eventually turned into auto-communicative processes that confirm and codify the joint understandings and (at least temporary) objectives.

In the light of these varying approaches to strategic innovation management, what can we learn from and how do we interpret the experiences of other European PSBs and other media institutions related to the implementation of innovative crossmedia production strategies? In this regard, an important study has been conducted by Jose A. García-Avilés (2012) in which he analysed and compared the relevant process innovations and strategy implementations at BBC News (the British PSB), The Guardian (UK newspaper), El Mundo (Spanish newspaper) and RTVE (Spanish PSB). All of these were good examples in terms of the management implementing special measures to systematically communicate the rationales and methods of change to the employees. Yet, quite often the strategies were constructed from a single point of view by the management (out of their perceptions of the environment), and therefore, the communications were also unidirectional - i.e., how and why to change the work routines or organisational structures as perceived by the management. Only The Guardian and RTVE were more systematic in terms of listening to the employees and thereupon modifying their strate- 
gies. All four of the analysed cases could be categorised as adaptive approaches to strategy development with The Guardian and RTVE having elements of an interpretative approach as defined by Küng. However, based on these four case studies, García-Avilés suggests his own "model of crossmedia innovation management" that is, in effect, similar to the interpretative approaches. To quote him:

The planning and execution of any crossmedia project must focus on communication, both internally to all professionals involved and externally to the audience, so that they will be aware of the changes ahead. Managers must consider gradually organizing the process of crossmedia implementation, in different stages, also recognizing and rewarding the additional skills acquired by journalists. Newsroom layout leads to developing enterprise architecture which could bring many advantages: improved decision making, elimination of inefficient and redundant processes, optimization of the use of organizational assets and minimization of employee turnover. Thus, the workflow process might be renovated, from assignment and production to content packaging and distribution. [---] Developing a crossmedia culture means that journalists must be open to sharing ideas and tips, bringing down traditional platform divisions, as well as increasing feedback, transparency and collaboration with users. Finally, management leadership is a pre-condition for any crossmedia project to be successful. (García-Avilés 2012: 272-273)

In this article we will examine the strategic management that has been used at ERR to carry out crossmedia-related reforms and what has been the role of organisation's management in this process.

\section{METHODOLOGY \\ AND RESEARCH QUESTIONS}

The purpose of this study was to understand how the cooperation across media platforms and between different editorial teams within ERR is organised at this point; is there any significant transformation taking place in the organisation and, if so, how is the change being led and driven? We will look at how people working for different platforms approach crossmedia production, what kind of related challenges they meet in their everyday tasks and how they contribute to the development of the new work routines, structures, rationales, and, all in all, the associated institutional strategy? These are our research questions:

$R Q 1$ : How is crossmedia production at ERR organised?

$R Q 2$ : How is the strategy for crossmedia production emerging at ERR?

To answer these questions we used two sets of qualitative methods: an analysis was conducted of the content of ERR's online platforms, together with its major crossmedia projects and a series of semistructured in-depth interviews were carried out.

The analysis of ERR's online and crossmedia content focused on a carefully selected corpus that consisted of most of the sub-pages of its official website as well as the YouTube or Facebook pages associated with ERR or its various TV programmes. The analysis focused on the semantic connections between the content on the Web and on ERR's other media platforms and channels. We sought to map the similarities, continuities, discontinuities, and distinctions between the different platforms and to interpret how the various crossmedia continuities had been created by ERR employees as of spring 2014.

The interview-based sub-study was preceded by a pilot study conducted in spring 2013 (the interviews were conducted by MA students in Crossmedia Production at Tallinn University's Baltic Film and 
Media School). This pilot study included 18 interviewees with different professional backgrounds at ERR. This study helped us to design our new study in terms of background knowledge and designing the sample. For the new study, the respondents were selected based on their roles in the organisation and with regard to their degree of involvement in ERR's various crossmedia productions. The chosen set of respondents included representatives at all managerial levels and from all editorial offices. Faceto-face interviews were conducted in March 2014 and lasted 45 minutes on average. On three occasions the interviews were completed either by e-mail or phone. In total, 14 face-to-face semi-structured interviews were conducted with the executive producers of the crossmedia-related projects and managers at ERR. All the interviews were audio recorded, transcribed, and, where relevant, translated from Estonian into English. Together with the pilot study our analyses included a total of 32 interviews. These were analysed using a basic form of discourse analysis that puts an emphasis on examining the relationships within the organisation. Recurrent themes and patterns across all the interviews were identified and analysed in respect to the research questions. As an outcome of the study, the patterns reflecting the strategic challenges and tensions related to cross-platform cooperation and crossmedia production were defined.

In addition to content analysis and interview-based study, a basic documentary analysis was also conducted of the relevant documents produced within ERR. The documentary analysis contributed to the research design (i.e., interview schedules) as well as to the eventual analysis.

\section{ERR'S MULTIPLATFORM PRESENCE}

ERR has two television channels, four radio channels, several web portals, and mobile apps adapted for different mobile platforms. Although we also interviewed ERR's radio professionals and analysed crossmedia projects that also included radio output, we decided to exclude the radio channels from the analysis in this paper.

ETV is ERR's flagship TV channel. It is a general interest TV channel broadcast in the Estonian language. The channel's main objective is to cover events that are important and significant both to the Estonian public and the state, and to be the centre and initiator of discussions relevant to society. The main distinctive feature of the programme is the high proportion of original programming in Estonian (6,000 hours a year) and the informative and social orientation of these programmes. ERR's second TV channel ETV2 is mainly designed for viewers with broader cultural interests. In addition, a few other target groups are served - children, sports fans, the Russianspeaking minority, etc. The aim of ETV2 is to provide cultural experiences, to offer the audience the possibility to enrich their worldview, to educate, and to inspire.

ERR's online media include the web portal ERR.ee and applications designed for use on mobile phones and tablets. The central portal ERR.ee consolidates various news websites (uudised.err.ee, rus.err. ee, news.err.ee, sport.err.ee, kultuur.err.ee, teadus.err.ee, menu.err.ee), as well as specialised services (including the weather, elections, and archives websites) and homepages for individual channels (etv.err. ee, vikerraadio.err.ee, etc.).

Targeting a broad audience, the general interest portal ERR.ee consolidates the latest news and content from ERR's various websites and programmes. The central portal serves as a gateway to all the ERR's programme homepages and websites. The websites are integrated, adding content extensions and extra info. All ERR programmes can be watched live online at otse.err.ee; all programmes can also be streamed for later viewing as a catch-up service. ERR's live broadcasts, archival materials, and news content can be viewed via mobile devices through a mobile-optimised website m.err.ee or via special applications adapted for major mobile platforms. Every TV and radio programme has its own homepage, with links to archived video and 
audio content (available for at least 30 days after the initial broadcast).

\section{THE CROSSMEDIA-RELATED OBJECTIVES OF ERR}

The ERR development plan is the official expression of its objectives and strategies. Pursuant to the Estonian Public Broadcasting Act, the development plan is prepared annually by ERR's management and covers the next financial year and three years thereafter. The current development plan presents ERR's general strategy for 2015-2018. The contents of the plan are, to an extent, discussed among most of the managers within the organisation. Yet, the plan is finalised by the executive board and voted (and therefore instituted) by its council whose members are external to the organisation (members of parliament and recognised media experts). This process effectively turns these documents into dialogues between the authorities and the PSB. Therefore it also reveals a very formal, top-down view of the organisation's strategic objectives.

According to the development plan for the years 2015-2018, greater emphasis will be placed on the cooperation between the television channels and the Internet portals and relevant investments provided. According to the plans described in the document, the television programmes will have to spend some of their budget (at least $3 \%$ for each programme) on producing content for online portals, websites, and social media. Another example is that ETV2 will have to continue its existing practice and organise theme weeks that are played out in much bigger ways in the society than simply putting out content for a TV programme. This includes organising seminars, releasing films in cinemas, organising other events, and producing experimental participatory media solutions online. However, all in all, the development plan for the next four years is somewhat vague when it comes to positioning the organisation in relation to convergence-related challenges and objectives. Yet, perhaps surprisingly, 15 out of the 36 objectives set by ERR for
2014 are related to crossmedia content or to developing crossplatform cooperation at ERR. Examples include plans for developing new programme formats to enable participation and debates between different interest groups; plans to develop programme formats for different screen sizes; plans to make the TV programming related to 2015 parliamentary elections truly interactive by cooperating with the main radio channel (Vikerraadio) and online portals; and plans for new interactive children's programme on Vikerraadio in cooperation with the children's portal meieoma.ee.

Aside from the officially expressed objectives of the organisation, we also asked our respondents to tell us what new objectives they perceived for the organisation. Two perceptions emerged repeatedly. Firstly, many justified the need for change with the changes in the environment. For instance, according to the editor-in-chief of portals:
It must be recognised where the most fervent competition in the media field is. It is on the Internet and it is not just the traditional portals, but specifically online videos, mobile services, etc. It is increasingly moving towards crossmedia.

Secondly, the need to attract younger audiences was a regularly expressed reason. The background is that, despite recent efforts, the audiences for both ERR's TV and radio programming are dominated by older target groups. Therefore, they also plan to extend their portfolio of platforms to meet the needs of the younger generation. The TV producers feel that the younger viewers demand a greater variety of content for viewing on different screens. As articulated by the head of ETV:

It is logical that the younger the viewer, the more he or she actually comes into contact with a variety of media devices. They watch big screens less and are 
more inclined to watch smaller ones. It is likely that, based on target group, the more entertaining and youthful the show the more it should relate to crossmedia; to either get the viewer in front of the big screen or to watch re-runs or some Internet portals discussing the show; or to involve the public in generating the added value for the show.

Here it should be noted that, be it the competitive environment, technological advancements, or younger audiences' perceived interests, all these justifications for potential new strategies are external. The potentials for new synergies, new services or actions that would emerge from unprecedented crossmedia cooperation were not mentioned by our interviewees. This may be because of the lack of the relevant discourses or discussions within the organisation.

\section{HOW THE SPREADING OF VIDEO CONTENT ACROSS PLATFORMS IS ORGANISED IN ERR}

The video content produced by ETV and ETV2 is currently distributed across several online platforms with occasional value added by creating extra content specifically for online audiences. Mostly, the purpose of such spreading is just to reuse the existing content and not so much to invest in providing additional platform-specific content. The video materials are presented on the ETV website (etv.ee) and on YouTube (ERR's has own channel) and in the thematic portals (for instance, news or entertainment portals use some of the video material originally produced for TV programmes. But how does this spreading take place? It provides work for the ETV webpage editor, for the ERR social media manager, and for editors working at the portals. The producers of the TV programmes are also responsible for the content in social media.

When it comes to small sub-pages on the ERR website that are dedicated to different TV programmes, these usually include information about the upcoming shows and video files of already broadcasted programmes. The programmes do not produce original content solely for these webpages, except on unique occasions when high priority programmes have invested in the production of web content. Yet, even in these instances, these new forms of content tend not to be aimed at "transmedia storytelling" - i.e. at extending the stories using the platform-specific affordances to reveal other angles of the stories. It should be emphasised that the webpages are not administered by the programmes themselves but by the web managers of ETV and ETV2 who upload the content received from the programmes.

When it comes to the spreading practices of the thematic portals, then a notable example is the entertainment portal called Menu. Menu has created unique content for the ETV programmes Perepidu, Klassikatähed, and Eesti Laul. The entertainment portal regularly publishes articles and also reuses video material from other ETV programmes. Therefore, it can be suggested that the thematic portals are most active in looking for new ways to create platformspecific extensions to content produced for other channels, and in general, to generate connections between the institution's different outlets.

\section{CONVERGENCE IN THE NEWSROOMS}

In terms of organisational structure and work routines, the radio and television news reporters and the portal editors still "live in separate worlds" as they are situated in different buildings. Radio and TV news are in fact headed by the same person (although the deputy of the head is mostly responsible for radio). Portals have an autonomous management. There are some crossmedia practices evident in the ERR newsroom, but these are rather limited. Journalists do not usually work for multiple platforms and having to work in different buildings slows down the communication between radio news, television news, and news por- 
tals. Usually one web editor attends the TV news meeting every morning to discuss the topics of the day. Sometimes they agree on the material that they will both use, or sometimes, if an interview is long and cannot be shown in full on TV, a longer version will be posted online. However this cooperation is not systematic. As of spring 2014 technical cooperation exists for the sharing of files produced by all parties as well as the transcriptions of the news stories. The application called iNews works as a database where all the upcoming and current news is posted and where everybody can also access the history of the daily news stories. This software makes it easy to take a story, adapt it, and publish it in different media. The content in the system is visible to all parties in real time. Stories that are not exclusive might be published on portals during the day. Still, the respondents stressed that daily cooperation is mainly related to meetings and file sharing.

The respondents also reported that, although crossmedia as a subject is occasionally discussed by the top managers, it has not materialised on a practical level in terms of clear changes in work routines. Our respondents in the news department argued that there is no vision in the organisation on how the cooperation between different news producers could be improved. Although the Head of News Service and his deputy expressed confidence that online portals are very important for ERR, they do not see an effective strategy that would support the development of portals. For instance, the Head of News Service and Head of Online Service share the view that the portals could take advantage of the high-quality video production that is available at ERR. This would give the portals a strong position and an advantage. But at the moment, there is no clear strategy for how the portals could maximise this advantage. There are also differences between the Head of Online Services and Head of News Services regarding what the focus point and strategy for the portals should be in the future. According to the head of television and radio news, the most important aspects should be rapid cooperation across media and delivering high-quality news content that strengthens the ERR news brand. Yet, currently, the portals are making an effort and using resources to broadcast live video streams from different events and establishing new theme portals, while complaining that they do not have sufficient resources to develop better cooperation and pay more attention on daily news production. However, despite the current differences, all the parties expressed hope that most of the problems will be resolved when all the news offices are united in the integrated newsroom in the same building in 2016 (the new building is currently under construction).

When it comes to the possibility of individual journalists working for different channels or platforms then, at the moment, journalists at ERR are not expected to work for multiple platforms nor to have the skills needed to produce modally different content (reporters in rural areas and abroad are exceptions). Yet, on special occasions when journalists have been interested in experimenting with working for other media, they have been supported by the management. The reasons why journalists choose to work for other or multiple platforms are usually related to financial considerations or motivated by the potential for personal development. The main reasons why people, who are working mainly for television, decide to sometimes work for other media were summarised as follows by the Head of Programmes of ETV:

Sometimes people are looking for an extra or part-time job in radio if their salary is not high enough, and managers also try to find extra work for their staff in other media just to keep them in the system when they cannot offer the workers sufficient workloads. They do so in order to ensure the staff's income during low periods. And that is normal, this is done everywhere. 
In conceptual terms it is argued (Quinn 2005) that it is specifically multi-skilled journalists that play an important role in crossmedia news production. Therefore, it has also been argued that "increased investment in multiplatform training should be made, particularly to provide greater understanding between television and digital media production cultures" (Bennett et al. 2012: 37). ERR's Head of Online Services is convinced that, if the journalists who are currently working on distinct platforms were given a chance to try out working in another medium, then this kind of exchange would increase the understanding about other media and the new social relationships would be good for better communication. Yet, he said that he does not believe that every journalist at ERR should necessarily contribute to multiple platforms as it may have a negative effect on the journalists' strengths (a good TV journalist may be a poor radio journalist and her/his TV stories will suffer if s/he is forced to produce for radio, as well). On the other hand, he explained that it is a case-by-case situation: some people may be successful and currently there are three people in the TV news office who are skilled and experienced in working for both television and radio. Although the managers of the newsrooms are not asking journalists to change their practices or forcing them to learn new skills, they still agree that, in the future, there will be a greater need for multi-skilled journalists. Recently, when new journalists have been hired for the television and radio newsrooms, candidates who are skilled at working in at least two media have been chosen.

As seen at ERR, the understanding about crossmedia is less about multi-functional journalists and more about understanding one another and increasing collaboration between distinct newsrooms. Therefore, crossmedia production in the ERR newsrooms is not discussed as a technology-driven process, but as a process that is primarily empowered by the communication and cooperation of journalists and secondly by the utilisation of technological innovation to achieve specific goals.

\section{COOPERATION OF PORTALS WITH OTHER CHANNELS}

As described above, currently the portals are trying to develop cooperation with radio and television through meetings and the sharing of content files. However, the daily communication between the different editorial offices can be too difficult to manage and this can also harm the cooperation. For instance, both sides may receive the information too late. On many occasions the portals do not have the time or opportunity to look for information or to arrange meetings to talk with radio and television editors or producers. At these times they ask for support from the marketing and communication department to find partners inside the organisation who can cooperate with them. As reflected by the Head of Online Services:

Currently marketing is trying to be the go-between. They have their own contact people, but it doesn't really function effectively, so we have to pay more attention to this in-house.

Again, testing different ways to establish contacts and secure communication channels in the organisation indicates that a universally accepted crossmedia strategy is missing within the organisation.

When it comes to organising larger media events such as the Olympic Games or, for instance, song contests, the portals have so far aimed at acting operatively in order to achieve close cooperation. Yet, in most cases, the preparation period has been very short and this has left little time for organising the cooperation needed to develop unique and innovative crossmedia forms. Additionally, executing innovative ideas can present technical challenges that may, in some cases, prove fatal to the good initiatives - especially when an idea that requires a unique technical solution is needed at the last minute and there is insufficient time to tackle the problem. In other words, the TV and online production cultures are in conflict due to their different production timelines. The TV production schedule is organised around the 
broadcast transmission dates leading to a culture that is at odds with digital production's iterative systems that synchronise project specifications, build site architecture, version, design, user-test, and reversion systems (Bennett et al. 2012:36). In digital content production, long-term and detailed planning is normally required, which involves longer production timelines that add greater value the longer before and after the programme airdate they extend. The television production culture leads to an expectation that changes can be made constantly until late in the production cycle, but in digital content production such changes would be very costly. The current understanding at ERR is that, in order to overcome the conflict and make the more innovative crossmedia forms possible, the organisation needs to adapt to the longer production cycles required by digital content production. The portals know that they need to start planning early and have a more systematic approach to developing collaboration.

\section{SPECIALISED PORTALS: MENU AND KULTUUR.ERR}

Below, we will take a look at the operations of two different thematic portals - Menu, the entertainment portal, and Kultuur.err, the culture and arts portal. For both, one of their set objectives is to extend the content of ERR's TV and radio programmes in the web. The year-old (at the time of the interviews) Menu has found good partners in radio and $T V$ and created diverse online extensions for many programmes. The culture portal was founded half a year later and therefore, creating the potential cooperation opportunities and expanding them in collaboration with TV and radio broadcasts are still in the development phase.

Menu's editorial team feels a strong need for crossmedia. Their work culture has developed in close connection to this concept.

Our job is largely to be a so-called "safe haven" and offer support to our other programmes: radio and TV. During the year that Menu has existed, we have cooperated as much as possible and now we have our own partners and internal connections with both radio and TV. (Editor in Chief, Menu)

Menu has developed good relationships with the editorial teams of ETV's entertainment and lifestyle programmes. Many producers working in those editorial teams already know how web portals can be useful for TV shows and vice versa. Menu also has good cooperation with Raadio 2 (the radio channel dedicated to new popular music and other pop-culture forms), which keeps a blog on the Menu portal. There has been a close partnership with Vikerraadio and Klassikaraadio as well. (Figure 1)

Most of the articles about television programmes are shorter versions of the television features, containing a short written text and embedded video footage from the television feature. Besides writing reviews, producing additional video material has been the principal way in which Menu has published additional content, while talking about various programmes. For example, Menu has video-recorded Vikerraadio's programme Luulelahing (Poetry Battle) and published it on its portal, giving readers a chance to see how radio broadcasts are made. A similar solution was also used in cooperation with Klassikatähed (Stars of Classical Music), when the portal installed a camera, which live-streamed what was happening behind stage during the show. That is, Menu is trying to present different angles to existing content on other platforms and in this way turn TV and radio programmes into multiplatform events. Similarly to the above, the Editor-in-Chief of Menu argued that the lack of more strategic cooperation and planning is one of the main obstacles to making more crossmedia projects happen at ERR:

Very often the problem is that we are such a large organisation and really huge and fascinating projects are being carried out 
here - TV does its own projects, radio its own, and we deal with our own projects here. But to get everyone together and create something really colossal somehow nobody has such an idea or if somebody has, then it is too late - by that time we are already in the middle of technical or financial difficulties, and cannot manage to get it done quickly. At the start they do not think enough about how to involve others in order to make a big project even bigger. The original plan is always very self-centred and only then do they start thinking about other possible directions to move in. They need to change such thinking. So that everybody understands that the greater their plan is at the very beginning, the even greater it can be in the end.

Kultuur.err, the arts and culture portal, is the newest in the portfolio of ERR thematic portals. It was established on 11 November 2013 and so far the cooperation with television and radio has been limited. The portal has been mainly disseminating information on the content of television and radio programmes with written articles, audio and video clips. The editors of the portal rarely add any extra information to the content they get from TV or radio. They are just publishing the trailers to promote upcoming television and radio programmes and, after the programme has been aired, the clip with the written article is published. In this way the portal is advertising television programmes like OP!, MI, Jüri Üdi Klubi, Kapital, and Kirjandusministeerium (various arts and culture programming). The written text, next to the promotional trailers, is usually very minimal and does not differ from the information published on the ERR television webpages (etv.ee; etv2.err.ee) - that is, they are recycling various marketing texts on programmes. Also the interview with the editor-in-chief of the portal showed that, at this stage, the culture portal makes a minimal effort to create value-adding extensions to radio or TV programmes.

We suggest that the differences between these two thematically related portals demonstrate not only the differences in experiences (one was more established, the other rather new at the time of the interviews), but how the crossmedia operations and developments in ERR depend more on the ideas and actions of individual employees and less on largescale and shared strategies. Our analysis suggests that the crossmedia added value was more significant in case of Menu than Kultuur.ee, but in the organisation this was not generally recognised, which may again indicate the lack of relevant discussions.

\section{FUTURE PERSPECTIVES FOR COOPERATION BETWEEN PORTALS AND CHANNELS}

When we were conducting interviews, the editors of the web portals invited other editorial teams to the meetings to find new opportunities for developing cooperation. The driving idea was that, despite the lack of additional resources necessary for crossmedia production, finding shared perspectives on the purposes of crossmedia could result in new cooperation opportunities without incurring any large supplementary costs. The following is how the Head of Online Service envisioned the ideal way for crossmedia cooperation in the immediate future.

In my opinion, we have reached the point at ERR where we should say that we have three equivalent outputs: TV, radio, and Internet. The development plan says so and this is constantly repeated by Margus Allikmaa [CEO of ERR], but in fact, we should take it a step further and realise that there is also crossmedia, which is not just TV, radio or Internet, but something different. This means that $1+1+1$ does not equal to 3 but 4 . The understanding of 


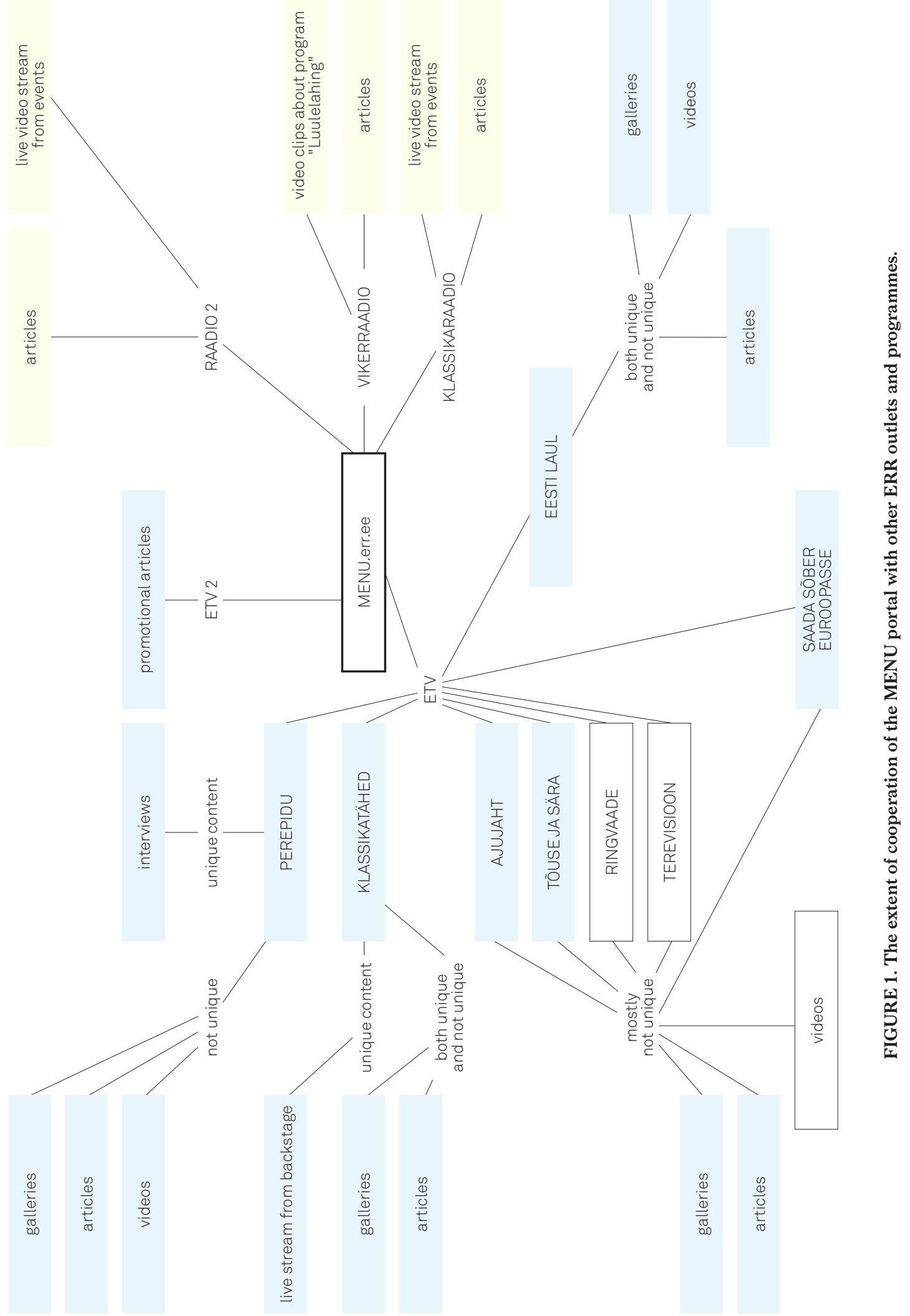


crossmedia is that it is not simply the Internet. At the moment, we do not organise meetings with the aim of discussing crossmedia, but we would like to suggest something as the "topic of the day". For example, different articles on the topic of the day would be published on our news portal several times during the day. The same topic would be mentioned on TV and radio as well. For example, on Ringvaade, they would similarly set things in motion, making reference to the topic on our portal. The topic would be summarised on the morning programmes like Vikerhommik or Uudis+ or on the evening broadcasts like Ringvaade or TV news. So the idea is that the organisation will have its common topics of the day. We have already discussed this idea with different parties.

\section{"FEWER, BIGGER, BETTER" AT ERR}

As already indicated above, ERR similarly to other broadcasters in Europe tends to invest relatively more into the crossmedia coverage of various larger events. In conceptual terms, this has generally been justified by the conflict between two closely related challenges: the need for high levels of creative and financial investment in new media and cross-platform projects and the generally limited returns from new platforms and the difficulties of evaluating value generated by cross-platform strategies. Doyle (2010: 444) argues that a common strategic response to these challenges has been to focus on fewer, high-impact ideas. For instance, the major UK broadcasters, generally seen as drivers of multiplatform strategising, have adopted the "fewer, bigger, better" formula and acknowledge that output diversity must suffer in order to support the selected projects with high-impact potential (Bennett et al. 2012: 51). At ERR, this means that, while the small number of bigger projects have more resources to spread content across multiple platforms, regularly broadcasted programmes, which have smaller budgets and smaller teams, have fewer possibilities for cooperating with other platforms and benefiting from the new crossmedia-related opportunities.

Yet, it can be argued that there is no clear strategy prioritising only larger events for crossmedia coverage at ERR. Currently there are no regulations established by the management that would specify that specific departments have to work together on collaborative crossmedia projects. Therefore it is entirely up to the content creators themselves whether, for instance, they create their content exclusively for TV or output additional content to other platforms. Therefore, the initiative for crossmedia projects, if it emerges at all, comes from the project management level and usually those occasions are related to nationally important events or projects like the Eesti Laul song contest. That is, the "obvious events" that take place and since all the individual platforms realise these should be covered, they eventually end up collaborating in various ways. Below, we look more closely at one of the relevant case studies.

\section{EESTI LAUL}

Eesti Laul is a national competition dedicated to popular music and organised annually by ERR. Although the winning song will represent Estonia at the international Eurovision Song Contest, the main goal of the competition is to promote local innovative pop music and to give musicians a chance to present themselves to a national audience.

The crossmedia production is organised so that there is one appointed individual, the "information manager", who is responsible for distributing the information to different platforms. She manages the information flow across platforms and promotes the broadcasting of the semifinals and the final concert. She is in close communication with the ERR's marketing department, providing them with information for producing promotional videos and 


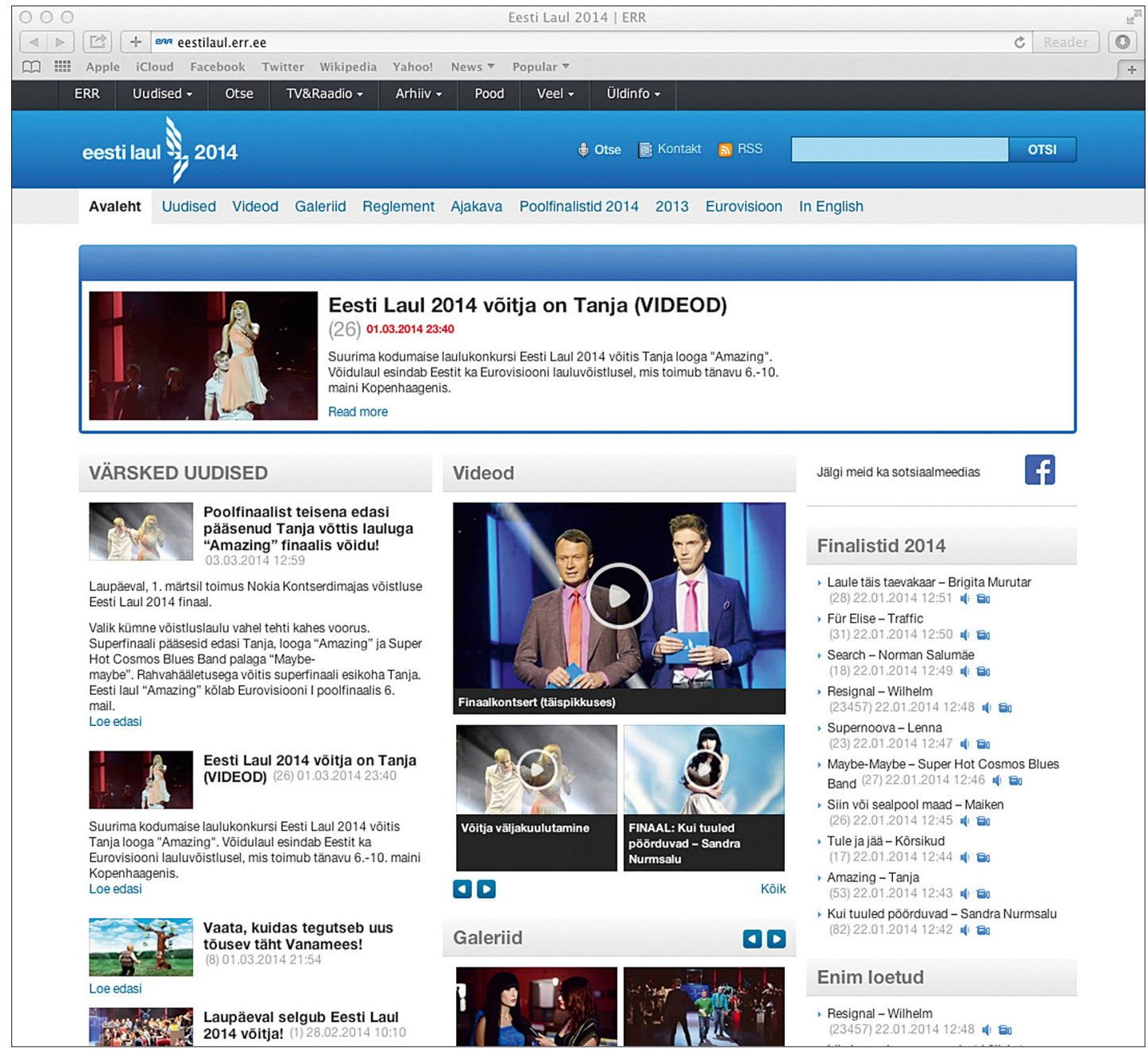

FIGURE 2. The webpage of Eesti Laul in May 2014. 
audio clips for TV and radio. In addition, this year, the information manager was also responsible for updating the Eesti Laul webpage. (Figure 2) The Eurovision Song Contest and Eesti Laul are two separate concepts, which is why the team of Eesti Laul does not think about what will happen after the competition. The person currently serving as information manager post was just hired for this year from outside the organisation. She developed her action plan based on the experiences and actions of her predecessor and later on adjusted it according to the circumstances. The information manager does not have a lot of control over how the content regarding Eesti Laul will reach the different channels or how the songs might change before the semi-finals or the final concert. Everything is determined by public interest and according to how each channel approaches the topic. The daily broadcasts on ETV, such as the breakfast programme Terevisioon or the afternoon infotainment programme Ringvaade, usually contribute to providing the audience with introductory "pre-stories" before the semi-finals. These two programmes are the main TV partners for most other large projects - they introduce, extend, and provide close-ups of different topics. The reason why these programmes tend to be included into more carefully coordinated crossmedia projects is that they effectively utilise a magazine-type format that enables them to be flexible and ready to cooperate on many occasions. While Terevisioon presented one new song every morning over several weeks, Ringvaade talked less about Eesti Laul, but they invited performers to be guests on the show, introduced the songs, and had their own unique way of presenting information regarding the contest. Neither the information manager nor any team member of Eesti Laul directly arranged the competition-related content on TV or radio.

One of the unique solutions for involving the members of the audience in the process was spontaneously developed at the initiative of an artist who was included in the project and had the idea of giving people a chance to decorate and draw on the photos of the finalists. Although this call to the audience came relatively late and without much preparation, the public reacted quickly, adopted the idea, and almost 2,000 people tried their hand at doodling on the photos. As a result, it could be said that Eesti Laul became more participatory accidentally at the initiative of the content producers. At the same time, the content offered on different channels was diverse and specific because each medium tried to take advantage of this topic by finding its own approach and adjusting it as it saw fit. The organiser of Eesti Laul did not coordinate the collaboration between the different platforms within ERR. According to the information manager there were also no meetings where the representatives of radio, TV, and Internet came together to discuss how to achieve greater synergy and present Eesti Laul in a more coordinated and meaningful manner. The key duties of the information manager of Eesti Laul were limited mostly to issuing press releases and managing the Facebook page. Yet, according to the producer of Eesti Laul, the information manager is supposed to be an important middleman between the different media. The information manager admitted that next year she will aim at developing a more comprehensive crossmedia strategy.

\section{THE MISSING STRATEGY}

All the above analyses on crossmedia cooperation practices within ERR - how newsrooms are cooperating; how the portals cooperate with other channels and platforms; how the crossmedia coverage of special events takes place - indicate that, in terms of its planning and management, crossmedia production happens rather spontaneously with very little detailed strategising. Despite the occasional statements from members of the executive management of ERR and convergence-related objectives in the official development plan of the organisation, most of our respondents acknowledged that there is no actual strategy. The middle managers at ERR did not see any clear strategy. The producers or project managers of the specific televi- 
sion programmes that were in some ways involved in crossmedia production were also not aware of any guidelines or frameworks for crossmedia production that could help them organise their work. For instance, in the words of the head of ETV:

Actually, this movement in the direction of crossmedia ... is more intuitive and spontaneous and is taking place independently in different areas.

The explanation by an ETV executive producer was similar:

It comes from the needs of the programme. We do not have extra people who can work only with information that needs to be directed through the most suitable channels to the most appropriate audience. Deciding where to place different information is more of a subconscious or intuitive process.

These statements evidence what we have demonstrated in the analyses above - although many crossmedia-like productions do take place (cross-platform extensions are produced or participatory affordances are utilised) - it all results from the actions or ideas of individual people and is not conditioned by systematic coordination framed by a generally accepted crossmedia strategy for the organisation. Below, we will review a set of factors that were evidenced in the interviews to serve both as indicators as well as causes for the lack of a strategy. First is the lack of dedicated resources. Expressed below from the perspective of the Head of Online Services:

If the budget is not increased, it means that the money for crossmedia has to come at the expense of other things, and this, in its turn, creates in-house opposition and stress. Theoretically people are in favour of certain things but, when it comes to carrying out the plans in practice, it means that some other things will be left undone or not done as well.

It was demonstrated above that, in the future, at least $3 \%$ of the budgets of all programmes will need to be dedicated to producing crossmedia extensions. However, in the spring of 2014 when the interviews were conducted, there were no targeted financial measures or incentives in place that would have supported the systematic cooperation between the editorial offices of the different channels and platforms or the creation of crossmedia innovations and provided added value to ERR's audiences.

The second factor that sets limits on crossmedia production at ERR is related to the first one. This is the lack of people and knowledge. Television producers tend to have too many responsibilities related to television production that keeps them from thinking about other platforms. A TV producer's first priority is the television programme and other platforms are considered only if extra time is available. As described by an executive producer of ETV:

Crossmedia is an option and the will exists in this regard, but it is quite often set aside because our clear priority is to produce the show. In many ways, ERR works like a conveyer belt and every day, I am putting out fires or dealing with programmes that are constantly on the air. So I am already expecting to be busy all the time. And when I realise that Klassikatähed [the programme that the interviewee also produces] is actually starting, I simply do not have time any more to think about all sorts of crossmedia outputs. In fact, if the person who is producing the show does not provide the necessary push, nobody will do much of anything. And the producer just does not have the time to provide any encourage- 
ment because s/he is making sure that the cameramen show up, the studio set is ready, and solving other practical problems related to the production. I think there really is a wish to make more use of crossmedia, but, in reality, it is employed only as much as the main tasks leave time for.

At the same time the managers cannot ask the producers to also work as multi-platform producers because this would require pay raises associated with these additional duties. Although there are signs that people understand the importance of crossmedia television, this has not been translated into concrete investments. If management sees value in crossmedia it should be reflected in the budget, which in turn would contribute to the evolution of the institutional crossmedia strategy from the ground up.

The third main obstacle that hinders cooperation across platforms and the development of functional crossmedia strategies is the existing organisational structure, and the spatial organisation of the editorial offices. Below, the related challenges are outlined by the ETV2 Head of Programme:

I think there is potential for something much greater than what is being done at the moment. But, yes, apparently the situation is influenced by the fact that our editorial offices are located in completely different places. It seems that communicating with one another requires an extra effort. And secondly, we have entirely different work schedules or we seem to think in completely different timeframes so that it can be half a year in advance or three months in advance at minimum. [---] This makes it a bit complicated.
From the management perspective, the changes in the structure would resolve the problems of poor communication. In the interviews, one vision of how structural changes could make a difference was expressed by the Head of Online Services:
Changing the structure could be one way to do these things. We even have a plan that by the year 2016 we have an integrated newsroom, so that we have TV, radio, and web news all together in one place. This already creates some opportunities. The next step would be to have all the editorial offices together in a similar way. For example, the team of Kapi- tal [a programme on economic affairs] could work together with the economy news editors in the web, radio, and TV. So that we would develop competence cen- tres. We do have great in-house potential. This applies not only to crossmedia, but to everything in general. But I think that chang- ing the in-house structure would also help the crossmedia function at ERR.

There were also other middle managers that shared the vision of such "creative centres" as the future editorial offices - competence centres where different kinds of media content are created for target audiences. The sharing and recurrence of the vision in the interviews indicated that the dialogues on the future of the organisation and its related crossmedia strategising have already started.

\section{CONCLUSION}

In the theory section of this article we demonstrated the richness of the challenges that larger media organisations may encounter when some sort of new crossmedia strategies are introduced. It was suggested that the management bears the core responsibility for carrying out such reforms 
- if the managers do not have a good understanding of how to lead the convergence process and what the rationales for crossmedia production are the whole process is destined to result in uncertainty and cause resistance. Our article demonstrated that although there is no significant resistance to working across platforms at ERR there is definitely a lot of uncertainty about the organisation's relevant goals and related practical steps. In this context, it would be easy to conclude that this article is about a failure. The lack of crossmedia-related strategising at ERR, if not apparent at first glance, was systematically demonstrated. Furthermore, as was also demonstrated in the theory section, there are plenty of examples in European media organisations that could be used for benchmarking the best practices. And there are significant potential benefits for PSBs in developing comprehensive institutional crossmedia strategies in terms of recycling content, and IPR, overcoming the technological fragmentation and divergence of media platforms, utilising the new affordances of digital media technologies, enabling participatory media experiences, furthering social dialogues, and empowering contemporary citizen-consumers. Against this background, the activities at ERR could be interpreted as somewhat disoriented - the rationales for the actions were generally unclear to the members of the organisation and the general institutional strategy was untraceable. Yet, we suggest that the situation should not be taken as a clear-cut managerial failure, but rather as a typical illustration of the challenges that an innovation-oriented organisation is undergoing in times of disruptive change in the form of media convergence.

Let us remember that ERR has been innovating comparatively aggressively. As was highlighted in the theory section, it is the public broadcasters that tend to drive innovation and experimentation with crossmedia strategies in Europe. In the Estonian context, this also applies to ERR - its online content offering is rich with dedicated thematic portals and award-winning mobile apps. All the radio and TV channels are available for live viewing online, with unprecedentedly rich options for catch-up viewing, and almost all of its digitised archive content is available for viewing too. As mentioned above, there are specific official objectives for further integration and cooperation across platforms and a joint newsroom will be built and completed in 2016. In terms of training, ERR has been developing cooperation with the Baltic Film and Media School in Tallinn that runs Crossmedia Production BA and MA programmes and this cooperation continues. ERR is providing scholarships for the students in these programmes. In this context, it should be recognised that, although there is a lack of a comprehensive strategy or articulated rationales for convergence and crossmedia at ERR, the general direction is still clear for both the organisation's employees as well as outside analysts and observers. Considering ERR's relatively limited funding, its achievements regarding the gained benefits from convergence are notable.

In terms of further managerial challenges and the next steps with regard to working towards developing more comprehensive crossmedia strategies, we propose that the initial experiences of the employees in the different editorial offices to innovate without much restriction could be turned into a strength. In the theory section, we introduced the interpretative approach to strategy development (as outlined by Küng 2008). In this context and to answer our initial research question: it can be suggested that this approach to strategy development related to crossmedia production has started to evolve at ERR organically, via everyday practices and incremental innovations within the organisation. Therefore we suggest that momentum already exists at ERR for further dialogic reflection on the existing experiences and learned lessons, for opening up new possibilities for interorganisational communication and reflection, and eventually for developing a consensus on new objectives and evolutionary trajectories for the organisation. After all, as explained above, all innovation is endogene- 
ously conditioned - via dialogues between subjects with different experiences, perspectives, and interpretations (Stark 2011). This article demonstrates the heterogeneity of experiences, perspectives, and interpretations at ERR. The momentum exists for the management of Estonia's public broadcaster to put these to good use. 


\section{REFERENCES}

Aarseth, Espen 2006. 'The Culture and Business of Cross-Media Productions.' - Popular Communication, 4, 3, 203-211.

Bardoel, Johannes; d'Haenens, Leen 2008. 'Public Service Broadcasting in Converging Media Modalities: Practices and Reflections from the Netherlands.' Convergence: The International Journal of Research into New Media Technologies, 14, 3, 351-360.

Bechmann, Anja 2012. 'Towards Cross-Platform Value Creation'. - Information, Communication \& Society, 15, 6, 888-908. doi:

http://dx.doi.org/10.1080/1369118X.2012.680483.

Bennett, James; Strange, Niki; Kerr, Paul; Medrado, Andrea 2012. Multiplatforming Public Service Broadcasting: The Economic and Cultural Role of UK Digital and TV Independents. London: Royal Holloway, University of Sussex, London Metropolitan University. Boczkowski, Pablo 2004. Digitizing the News: Innovation in Online Newspapers. Cambridge: MIT Press.

Born, Giorgina 2004. Uncertain Vision: Birt, Dyke and the Reinvention of the BBC. London: Secker \& Warberg. van den Bulck, Hilde; Tambuyzer, Sil 2013. 'Collisions of Convergence: Flemish News Workers' and Management's Perceptions of the Impact of PSB Newsroom Integration on Journalistic Practices and Identities.' International Communication Gazette, 75, 1, 54-75. Caldwell, John T. 2006. 'Critical Industrial Practice: Branding, Repurposing, and the Migratory Patterns of Industrial Texts'. - Television \& New Media, 7, 2, 99-134. Chan-Olmsted, Sylvia M. 2005. 'Response to "Diversification Strategy of Global Media Conglomerates: A Comment"'. - Journal of Media Economics, 18, 2, 105-107.

Chan-Olmsted, Sylvia M.; Chang, Byeng-Hee 2003. 'Diversification Strategy of Global Media Conglomerates: Examining Its Patterns and Determinants'. Journal of Media Economics, 16, 4, 213-233. http://www.informaworld.com/smpp/content $\sim \mathrm{db}=$ all c ontent=a785348100 (20 October 2014).

Chan-Olmsted, Sylvia M.; Chang, Byeng-Hee 2006.

'Mobile Wireless Strategy of Media Firms: Examining the Wireless Diversification Patterns of Leading Global Media Conglomerates'. - Jo Groebel, Eli M. Noam, Valierie Feldmann (eds.), Mobile Media: Content and Services for Wireless Communications. Mahwah: Lawrence Erlbaum Associates Publishers, 165-183. Chapain, Caroline; Cooke, Phil; de Propis, Lisa; MacNeill, Steward; Mateos-Garcia, Juan 2010. Creative Clusters and Innovation: Putting Creativity on the Map. London: NESTA.

Cottle, Simon; Ashton, Mark 1999. 'From BBC Newsroom to BBC Newscentre - On Changing Technology and Journalist Practices. - Convergence: The International Journal of Research into New Media Technologies, 5, 3, 22-43.

Creeber, Glen; Hills, Matt 2007. 'TVIII: Into, or Towards, a New Television Age?'. - New Review of Film and Television Studies, 5, 1, 1-4.

Dailey, Larry; Demo, Lori; Spillman, Mary 2005. 'The Convergence Continuum: A Model for Studying Collaboration Between Media Newsrooms'. - Atlantic Journal of Communication, 13, 3, 150-168.

Debrett, Mary 2009. 'Riding the Wave: Public Service Television in the Multi-platform Era'. - Media, Culture \& Society, 31, 5, 807-827. doi:10.1177/0163443709339466. Deuze, Mark 2004. 'What Is Multimedia Journalism?' Journalism Studies, 5, 2, 139-152.

Doyle, Gillian 2010. 'From Television to Multi-Platform: Less from More or More for Less?' - Convergence:

The International Journal of Research into New Media Technologies, 16, 4, 431-449.

Erdal, Ivar John 2007. 'Negotiating Convergence in News Production. - Tanja Storsul, Dagny Stuedahl (eds.), Ambivalence Towards Convergence: Digitalization and Media Change. Göteborg: Nordicom, 73-85.
Erdal, Ivar John 2009. 'Cross-Media (Re)Production Cultures'. - Convergence: The International Journal of Research into New Media Technologies, 15, 2, 215-231. Fagerjord, Anders; Storsul, Tanja 2007. 'Questioning Convergence.' - Tanja Storsul, Dagny Stuedahl (eds.), Ambivalence Towards Convergence: Digitalization and Media Change. Götenborg: Nordicom, 19-31.

Foucault, Michel 2002. Power: The Essential Works of Foucault 1954-1984. Vol. 3. Ed. James D. Faubion, trans. Robert Hurley. London: Penguin.

García-Avilés, Jose A. 2012. 'Innovation Management in Crossmedia Production: Leading Change in the Newsroom'. - Indrek Ibrus, Carlos A. Scolari (eds.), Crossmedia Innovations: Texts, Markets, Institutions. Frankfurt: Peter Lang, 259-276.

Huang, Edgar; Rademakers, Lisa; Moshood,

A. Fayemiwo; Dunlop, Lillian 2004. 'Converged Journalism and Quality: A Case Study of the Tampa Tribune News Stories'. - Convergence: The International Journal of Research into New Media Technologies, 10, 4, 73-91. Huntsberger, Michael 2008. 'Create Once, Play Everywhere: Convergence Strategies for Public Radio in the U.S.' Paper presented at the RIPE 2008, Mainz, Germany. Ibrus, Indrek 2013. 'Evolutionary Dynamics of the Mobile Web' - John Hartley, Axel Bruns, Jean Burgess (eds.), A Companion to New Media Dynamics. London: Blackwell, 277-289.

Ibrus, Indrek 2014a. 'Dialogic Control: Power in Media Evolution'. - International Journal of Cultural Studies, doi:10.1177/1367877914528117.

Ibrus, Indrek 2014b. 'Path Dependencies in Media Design: Evolutionary Dynamics of Early Mobile Web and Its Textual Forms'. - Social Semiotics, 24, 2, 191-208. doi :10.1080/10350330.2013.859479.

Ibrus, Indrek; Ojamaa, Maarja 2014. 'What Is the Cultural Function and Value of European Transmedia Independents?'. - International Journal of Communication, 8, 2283-2300. http://ijoc.org/index.php/ijoc/article/ view/2650/1204 (20 October 2014).

Ibrus, Indrek; Scolari, Carlos A. 2012. 'Introduction: Crossmedia Innovation?' - Indrek Ibrus, Carlos A. Scolari (eds.), Crossmedia Innovations: Texts, Markets, Institutions. Frankfurt: Peter Lang, 7-21.

Iosifidis, Petros 2010. 'Introduction'. - Petros Iosifidis (ed.), Reinventing Public Service Communication: European Broadcasters and Beyond. Basingstoke: Palgrave, 1.

Kolo, Castulus; Vogt, Patrick 2003. 'Strategies for Growth in the Media and Communications Industry: Does Size Really Matter?' - International Journal of Media Management, 5, 4, 251-261.

Küng, Lucy 2008. Strategic Management in the Media: From Theory to Practice. London: Sage.

Ludwig, Johannes 2000. 'The Essential Problem of the Media: Working between Market Failure and Cross-financing. - Journal of Media Economics, 13, 3, 187-200. Mansell, Robin 2014. 'Power and Interests in Information and Communication Technologies and Development: Exogenous and Endogenous Discourses in Contention'. - Journal of International Development, 26 , $1,109-127$.

Moe, Hallvard 2008. 'Public Services Online? Regulating Public Broadcasters' Internet Services - A Comparative Analysis'. - Television and New Media, 9, 3, 220-238.

Porter, Michael E. 1998. Competitive Strategy: Techniques for Analyzing Industries and Competitors. New York: Free Press.

Quinn, Stephen 2005. 'Convergence's Fundamental Question'. - Journalism Studies, 6, 1, 29-38. Silcock, B. William; Keith, Susan 2006. 'Translating the Tower of Babel? Issues of Definition, Language, and Culture in Converged Newsrooms. - Journalism Studies, 7, 4, 610-627.

Singer, Jane B. 2004. 'Strange Bedfellows? The Diffusion of Convergence in Four News Organisations'. Journalism Studies, 5, 1, 3-18. 
Soun Chung, Deborah 2007. 'Profits and Perils: Online News Producers' Perceptions of Interactivity and Uses of Interactive Features.' - Convergence: The Interna-

tional Journal of Research into New Media Technologies, 13, 1, 43-61. doi:10.1177/1354856507072856.

Stark, David 2011. The Sense of Dissonance:Accounts of Worth in Economic Life. Princeton: Princeton

University Press.

Suárez Candel, Roberto 2012. Adapting Public

Service Broadcasting to the Multiplatform Scenario - Challenges, Opportunities \& Risks. Working Papers of the Hans Bredow Institute, vol. 25. Hamburg: Hans Bredow Institute for Media Research.

Tidd, Joe; Bessant, Joe 2009. Managing Innovation: Integrating Technological, Market and Organizational Change. Chichester: John Wiley \& Sons.

Trappel, Josef 2008. 'Online Media within the Public Service Realm? Reasons to Include Online into the Public Service Mission'. - Convergence: The International Journal of Research into New Media Technologies, 14, 3, 313-322.

Witschge, Tamara; Nygren, Gunnar 2009. ‘Journalism: A Profession under Pressure?' - Journal of Media Business Studies, 6, 1, 37-59. 